\title{
Inhibition of JNK Enhances TGF- $\beta 1$-Activated Smad2 Signaling in Mouse Embryonic Lung
}

\author{
SHU WU, KALYANI KASISOMAYAJULA, JINGHONG PENG, AND EDUARDO BANCALARI \\ Department of Pediatrics, University of Miami Miller School of Medicine, Miami, Florida 33101
}

\begin{abstract}
The Smad2/3 pathway plays a key role in mediating TGF- $\beta 1$ inhibition of branching morphogenesis and induction of connective tissue growth factor (CTGF) expression in embryonic lungs. Because a number of cell-specific interactions have been described between TGF- $\beta 1$-driven Smad signaling and the c-Jun $\mathrm{N}$-terminal kinase (JNK) pathway, we have investigated the effects of JNK inhibition on TGF- $\beta 1$ activation of Smad2, inhibition of branching, induction of CTGF expression, and apoptosis in mouse embryonic lung explants. Mouse embryonic day 12.5 (E12.5) lung explants were treated with TGF- $\beta 1$ in the presence or absence of a specific pharmacologic JNK inhibitor (SP600125) and a specific JNK peptide inhibitor (JNKI). We found that TGF- $\beta 1$ activated the JNK pathway by stimulating c-Jun phosphorylation, which was blocked by JNK inhibitors. Treatment with SP600125 stimulated Smad2 phosphorylation and enhanced TGF- $\beta 1$-induced Smad 2 phosphorylation. Treatment with JNK inhibitors also decreased normal branching morphogenesis and induced CTGF expression as well as augmented TGF- $\beta 1$ inhibition of branching and induction of CTGF expression. Furthermore, JNK inhibition-induced apoptosis. Our results demonstrate that inhibition of the JNK pathway promotes TGF- $\beta 1$-driven Smad2 responses in lung branching morphogenesis. These data suggest that the JNK pathway may antagonize TGF- $\beta 1$ dependent Smad2 signaling during mouse embryonic lung development. (Pediatr Res 65: 381-386, 2009)
\end{abstract}

$\mathrm{T}^{\circ}$ GF- $\beta 1$ is a multifunctional cytokine that regulates diverse biologic processes, including cell proliferation, differentiation, and apoptosis during development and tissue injury repair $(1,2)$. Both in vivo studies in transgenic mice and in vitro studies in embryonic lung organ culture have demonstrated that TGF- $\beta 1$ is a key negative regulator for embryonic lung branching morphogenesis (3-7). However, the molecular mechanisms mediating TGF- $\beta 1$ cellular responses in lung development are not well understood.

TGF- $\beta 1$ initiates its cellular action by inducing heterodimerization of type I (T $\beta R I)$ and type II (T $\beta R I I)$ transmembrane TGF- $\beta$ receptors $(8,9)$. On ligand-induced dimerization, constitutively active T $\beta$ RII kinase phosphorylates $\mathrm{T} \beta \mathrm{RI}$ that, in turn, activates the downstream signal transduction cascades. Smad2 and Smad3 phosphorylation is the most prominent pathway $(10,11)$. Smad7 is an inducible intracellular inhibitor that decreases $\operatorname{Smad} 2 / 3$ phosphorylation by

Received July 18, 2008; accepted November 9, 2008

Correspondence: Shu Wu, M.D., Department of Pediatrics/Division of Neonatology, Batchelor Children's Research Institute, University of Miami Miller School of Medicine, PO Box 016960, Miami, FL 33101; e-mail: swu2@med.miami.edu

Supported, in part, by grant K08 HD046582 from NIH, by Project NewBorn University of Miami, and by a grant from the Bank of American Charitable Foundation, Inc. blocking their access to TGF- $\beta$ receptors (12). Once activated, Smad2/3 associates with Smad4 and translocates to the nucleus, where the complex transcriptionally regulates expression of target genes.

Besides the Smad2/3 pathway, TGF- $\beta$ can also activate the c-Jun NH2-terminal kinase (JNK) signaling pathway (13-16). The activation of the c-Jun N-terminal kinase (JNK) pathway by TGF- $\beta 1$ is mediated through sequential phosphorylation and activation of mitogen-activated protein kinase (MAPK) kinase 1, then MAPK kinase (MKK) 4 or MKK 7 and finally JNK. JNK then translocates to the nucleus where it phosphorylates c-Jun. Activated c-Jun homodimerizes with the members of the Jun family or heterodimerizes with the members of the Fos family. Such complexes named activating-protein-1 (AP-1) bind to AP-1 sites and can control the expression of a number of genes (17-19). There is growing evidence that the JNK pathway can cross talk with the TGF- $\beta$-dependent Smad signaling at multiple sites and both positively and negatively modulate TGF- $\beta$ induced gene expression and cellular responses $(20,21)$.

We and others have previously demonstrated the critical role of the Smad2/3 pathway in mediating TGF- $\beta 1$ inhibition of branching morphogenesis in mouse embryonic lung explants $(22,23)$. Connective tissue growth factor (CTGF) is a member of a family of immediate-early gene products that coordinate complex biologic processes during differentiation and tissue repair $(24,25)$. TGF- $\beta 1$ is a major inducer of CTGF expression in mesenchymal type cells and many of the TGF- $\beta 1$ effects on mesenchymal cells, including stimulation of fibroblast proliferation; ECM production and myofibroblast differentiation are mediated by CTGF (26-29). We have provided evidence that endogenous and TGF- $\beta 1$-induced CTGF expression in embryonic lung explants is mediated by the Smad2 pathway (22). Moreover, like TGF- $\beta$, CTGF inhibits branching morphogenesis (22).

Because the JNK pathway cross talks with the Smad2/3 pathway and the Smad2/3 pathway is crucial in mediating TGF- $\beta$ inhibition of branching and induction of CTGF expression, we postulated that the JNK pathway would play a

Abbreviations: AP-1, activating-protein-1; CTGF, connective tissue growth factor; JNK, c-Jun NH2-terminal kinase; JNKI, JNK peptide inhibitor; JNKC, JNK peptide control; MAPK, mitogen-activated protein kinase; MKK, MAPK kinase; p-c-Jun, phosphorylated c-Jun; p-Smad2, phosphorylated smad2; T $\boldsymbol{\beta}$ RI, TGF- $\beta$ receptor I; T $\boldsymbol{\beta}$ RII, TGF- $\beta$ receptor II; $\mathbf{t}-\mathbf{c}-\mathbf{J u n}$, total c-Jun; t-Smad2, total Smad2 
pivotal role in branching morphogenesis and CTGF expression in embryonic lung explants. Hence, we investigated the effect of blocking the JNK pathway with SP600125, a specific pharmacologic inhibitor (30) and with a specific peptide inhibitor of JNK (JNKI) (31), on Smad2 phosphorylation, CTGF induction, branching inhibition, and apoptosis. Our results demonstrate that inactivation of the JNK pathway enhances TGF$\beta$-dependent Smad2 signaling and induces apoptosis in embryonic lung explants.

\section{MATERIALS AND METHODS}

CD1 mice were purchased from Harlan (Indianapolis, IN). Trizol reagents and first strand cDNA synthesis kits were obtained from Invitrogen (Carlsbad, CA). Recombinant TGF- $\beta 1$ and a pan TGF- $\beta$ neutralizing antibody (clone 1D11) were purchased from R\&D Systems (Minneapolis, MN). SP600125, a chemical inhibitor of JNK with IC50 of 0.04 (30) was obtained from EMD Chemicals (San Diego, CA). JNKI and JNKC (control peptide for JNKI) were obtained from Alexis Biochemicals (San Diego, CA). Primers and reagents for quantitative real-time RT-PCR were purchased from Applied Biosystems (Foster City, CA). A rabbit polyclonal antibody for phosphorylated smad2 (p-Smad2) was from Chemicon (Temecula, CA). Rabbit polyclonal antibodies for phosphorylated c-Jun (p-c-Jun) and total c-Jun (t-c-Jun), and a MAb for cleaved caspase 3 were obtained from Cell Signaling Technology (Denver, MA). Goat polyclonal antibodies for CTGF and total Smad2/3 (t-Smad2/3) were obtained from Santa Cruz Biotechnology Inc (Santa Cruz, CA). A mouse MAb for $\beta$-actin was obtained from Sigma Chemical Co. (St. Louis, $\mathrm{MO}$ ). Horseradish peroxidase conjugated anti-mouse, anti-rabbit and antigoat IgGs and enhanced chemiluminescence reagents were obtained from Amersham (Piscataway, NJ).

Embryonic lung explant culture. The study protocol was reviewed and approved by the Animal Care and Use Committee of the University of Miami. Eight-week-old female mice were mated, and noon on the day of vaginal plug formation was set as E0.5. On E12.5, pregnant mice were killed by cervical dislocation after receiving $\mathrm{CO}_{2}$ narcosis. Embryos were obtained by hysterectomy. Lungs were dissected under a dissection microscope and placed on $8-\mu \mathrm{m}$ nucleopore membranes floating on $0.5 \mathrm{~mL}$ of chemical defined serumfree medium in each well of a 24-well plate as previously described (22). The lung explants were preincubated with inhibitors, JNKC, or TGF- $\beta$ neutralizing antibodies for $1 \mathrm{~h}$ and then treated with TGF- $\beta 1$. Cultures were maintained at $37^{\circ} \mathrm{C}$ in a humidified $5 \% \mathrm{CO}_{2}$ incubator for $2-48 \mathrm{~h}$. The lung explants exposed to medium alone served as controls.

Quantification of branching morphogenesis. Branching morphogenesis was measured as the number of the terminal sacs around the circumference of the lung explants as previously described (22). Lung explants in culture on the nucleopore membranes were photographed at $48 \mathrm{~h}$ using an Olympus digital camera attached to an inverted microscope for permanent imaging analysis.

RNA isolation and quantitative real-time RT-PCR. Total RNA was isolated from pooled lung explants as described (22). Two $\mu \mathrm{g}$ of total RNA was reverse-transcribed in a $20 \mu \mathrm{L}$ reaction by using a first-strand cDNA synthesis kit according to manufacturer's protocol (Invitrogen). The Realtime RT-PCR was performed on an ABI Fast 7500 System (Applied Biosystems). Each reaction included diluted first-strand cDNA, mouse CTGF, TGF- $\beta 1$, TGF- $\beta 2$, TGF- $\beta 3$, T $\beta$ RI, T $\beta$ RII, or GAPDH primers, and master mix containing TaqMan probes according to the manufacturer's instruction (Applied Biosystems). Real-time RT-PCR conditions were $95^{\circ} \mathrm{C}$ for $10 \mathrm{~min}$, followed by 40 cycles of $95^{\circ} \mathrm{C}$ for $15 \mathrm{~s}$, and $60^{\circ} \mathrm{C}$ for $30 \mathrm{~s}$. RNase-free water was used as a negative control. For each target gene, a standard curve was established by performing a series of dilutions of the first-strand cDNA. The mRNA expression levels of target genes were determined from the standard curve and normalized to GAPDH.

Western blot analysis. Total protein was extracted from pooled lung explants with a lysis buffer from Active Motif (Carlsbad, CA), according to manufacturer's protocol as previously described (22). The protein concentrations were measured by BCA protein assay using a commercial kit from Pierce Biotechnology (Rockford, IL). Seventy-five microgram samples of total protein were fractionated by SDS-PAGE on 4-12\% Tris-glycine precast gradient gels (Invitrogen) and then transferred to nitrocellulose membranes (Amersham, Piscataway, NJ). The membranes were incubated overnight at $4^{\circ} \mathrm{C}$ with primary antibodies specific to proteins of interest and then incubated for $1 \mathrm{~h}$ at room temperature with HRP-conjugated secondary antibodies. Antibody-bound proteins were detected using ECL chemiluminescence methodology. Membranes were then stripped with $0.2 \mathrm{~N} \mathrm{NaOH}$ and reincubated with primary antibodies reactive with normalization proteins. The intensities of protein bands were quantified by Quantity One Imaging Analysis Program (Bio-Rad, Hercules, CA). The relative protein levels of CTGF and cleaved caspase 3 were normalized to $\beta$-actin, $\mathrm{p}$-Smad2 levels were normalized to $\mathrm{t}$-Smad2 and p-c-Jun levels were normalized to t-c-Jun.

DNA fragmentation assay. DNA was isolated from pooled lung explants as described (32). The DNA ( $1 \mu \mathrm{g} / \mathrm{lane})$ was electrophoresed on a $1.5 \%$ agarose gel. The gel was stained with ethidium bromide and photographed under transmitted UV light.

Data presentation and statistical analysis. Results are expressed as means \pm SD. Comparisons were performed by one-way ANOVA followed by Student-Newman-Keuls test. A $p<0.05$ was considered significant.

\section{RESULTS}

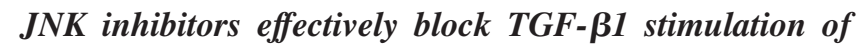
$c$-jun phosphorylation. We first examined c-Jun phosphorylation to determine if TGF- $\beta 1$ can activate the JNK pathway and whether SP600125 and JNKI can block the JNK pathway. As demonstrated in Figure 1, treatment with TGF- $\beta 1$ resulted in c-Jun phosphorylation. However, preincubation with SP600125 or JNKI abolished TGF- $\beta 1$ induced c-Jun phosphorylation. These results demonstrate that TGF- $\beta 1$ activates the JNK pathway, which can be effectively blocked by JNK inhibitors.

Blocking the JNK pathway augments endogenous and TGF-ß1-induced Smad2 phosphorylation. To determine whether cross talk occurs between the JNK and Smad2 pathways in response to TGF- $\beta 1$, we examined the effect of JNK inactivation on Smad2 phosphorylation. As we have demonstrated previously, treatment with TGF- $\beta 1$ induces sustained Smad2 phosphorylation (Fig. 2). Interestingly, treatment with SP600125 alone induced Smad2 phosphorylation and treatment with SP600125 plus TGF- $\beta 1$ induced a greater Smad2 phosphorylation (Fig. 2). Treatment with JNKI or JNKC did not affect TGF- $\beta 1$ phosphorylation of Smad2 (data not shown).

Blocking the JNK pathway inhibits branching morphogenesis and enhances TGF-ß1 inhibition of branching. We have previously shown that inactivation of the Smad2 pathway increases normal branching morphogenesis and blocks TGF- $\beta 1$ inhibition of branching in E12.5 lung explants (22). We hypothesized that the JNK pathway antagonizes the Smad2 pathway. Therefore, blocking the JNK pathway would enhance Smad2 signaling that results in branching inhibition. As demonstrated in Figure 3, treatments with a low-dose of SP600125 or TGF- $\beta$ did not affect branching morphogenesis;

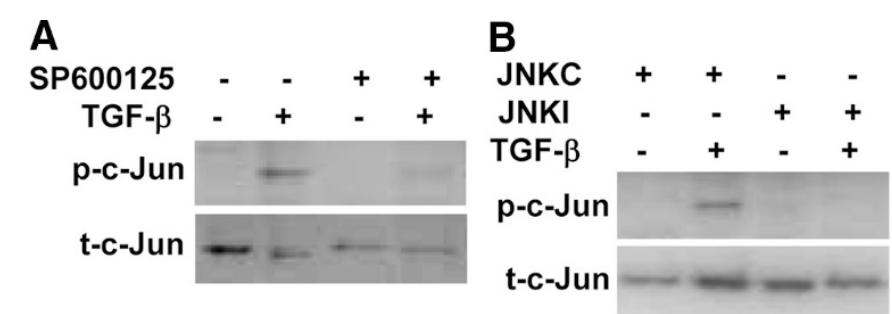

Figure 1. TGF- $\beta 1$ activates the JNK pathway by inducing c-Jun phosphorylation. A: E12.5 lung explants were treated with $10 \mu \mathrm{M} \mathrm{SP600125,} 100 \mathrm{ng} / \mathrm{mL}$ TGF- $\beta 1$ or their combination for $48 \mathrm{~h}$. $B$ : E12.5 lung explants were treated with $10 \mu \mathrm{M}$ JNKI, $10 \mu \mathrm{M}$ JNKC, $100 \mathrm{ng} / \mathrm{mL}$ TGF- $\beta 1$ or their combination for $48 \mathrm{~h}$. Western blot was performed to analyze expression of p-c-Jun and t-c-Jun. The relative p-c-Jun expression levels were normalized to t-c-Jun. 
A

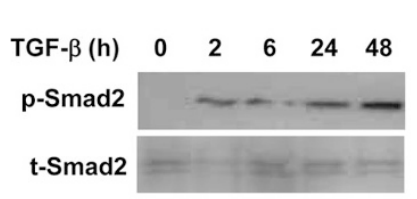

B

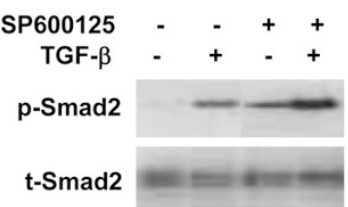

C

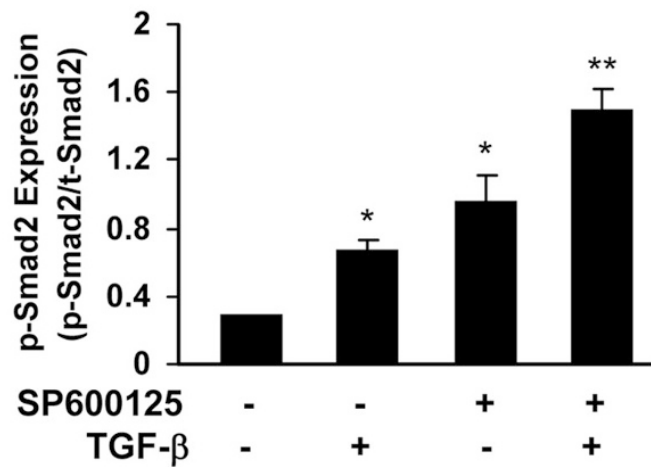

Figure 2. Treatment with SP600125 induces endogenous Smad2 phosphorylation and enhances TGF- $\beta 1$ phosphorylation of Smad2. A: E12.5 lung explants were treated with $100 \mathrm{ng} / \mathrm{mL}$ of TGF- $\beta$ for $2-48 \mathrm{~h}$. $B$ : E12.5 lung explants were treated with $10 \mu \mathrm{M} \mathrm{SP} 600125,100 \mathrm{ng} / \mathrm{mL}$ TGF- $\beta 1$ or their combination for $48 \mathrm{~h}$. Western blot was performed to analyze p-Smad2 and t-Smad2 expression. $C$ : The relative p-Smad2 expression levels were normalized to $\mathrm{t}-\mathrm{Smad} 2$. Data are mean $\pm \mathrm{SD}$ from three separate experiments. ${ }^{*} p<0.001$ compared with the control. ** $p<0.001$ compared with TGF- $\beta 1$. however, the combination of the two decreased branching by $30 \%$. Treatment with $10 \mu \mathrm{M}$ SP600125 or JNKI alone decreased normal branching morphogenesis by 55 and $35 \%$. The combination of a high-dose of TGF- $\beta 1$ with SP600125 or JNKI resulted in further decrease of branching up to $75 \%$. Treatment with low-dose of JNKI $(1 \mu \mathrm{M})$ did not affect normal branching or TGF- $\beta 1$ inhibition of branching (data not shown).

Blocking the JNK pathway induces endogenous CTGF gene expression and enhances TGF-ß1-induced CTGF gene expression. In a previous study, we showed that endogenous and TGF- $\beta 1$-induced CTGF expression in embryonic lung explants is Smad2-dependent (22). We analyzed the effect of SP600125 and JNKI on endogenous and TGF- $\beta 1$ induced CTGF gene expression. As demonstrated in Figure 4, compared with the control, treatment with TGF- $\beta 1$ increased CTGF mRNA expression by nearly 5-fold. Lung explants treated with SP600125 also showed a 4-fold increase of CTGF mRNA expression. However, the combination of SP600125 and TGF- $\beta 1$ treatment resulted in a 14-fold increase of CTGF mRNA expression (Fig. 4). Consistent with CTGF mRNA expression, treatment with SP600125 or TGF- $\beta 1$ alone induced 1.6- and 2-folds increase in CTGF protein expression, and treatment with SP600125 plus TGF- $\beta 1$ induced more than a 3-fold increase in CTGF protein expression (Fig. 4). Treatment with JNKI resulted in similar changes of CTGF mRNA expression (Fig. 4). These results demonstrate that blocking
A

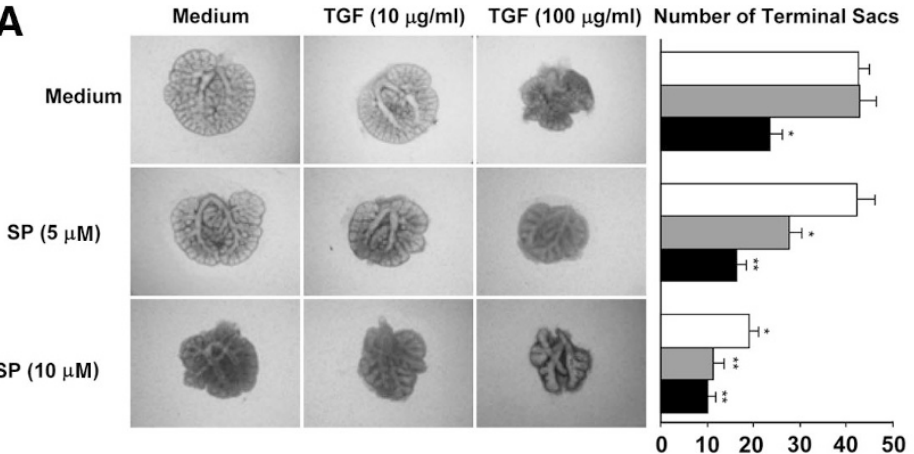

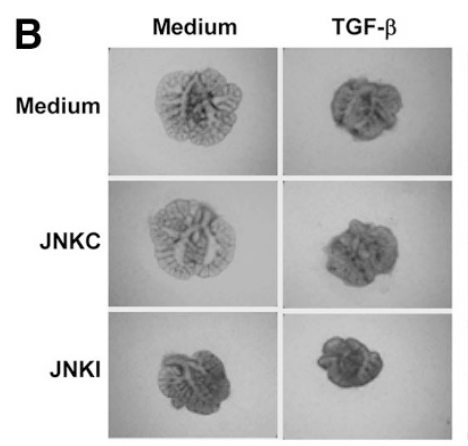

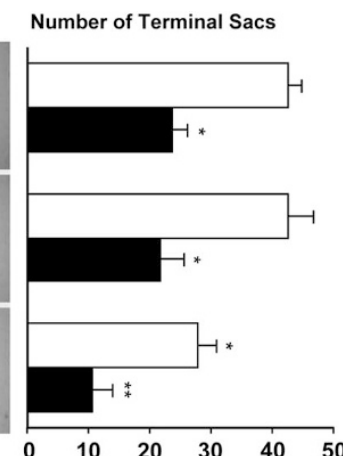

Figure 3. JNK inhibitors decrease normal branching and augment TGF- $\beta 1$ inhibition of branching. A: E12.5 lung explants were treated with SP600125 $(5,10 \mu \mathrm{M})$, TGF- $\beta 1(10,100 \mathrm{ng} / \mathrm{mL})$, or their combinations for $48 \mathrm{~h} . B$ : E12.5 lung explants were treated with $10 \mu \mathrm{M} \mathrm{JNKI}, 10 \mu \mathrm{M} \mathrm{JNKC,} 100 \mathrm{ng} / \mathrm{mL}$ TGF- $\beta 1$, or their combination for $48 \mathrm{~h}$. The number of terminal sacs was counted. Each bar represents mean \pm SD from six to eight lung explants (open bar, absence of TGF- $\beta 1$; gray bar, TGF- $\beta 110 \mathrm{ng} / \mathrm{mL}$; black bar, TGF- $\beta 1100 \mathrm{ng} / \mathrm{mL}$ ). ${ }^{*} p<0.001$ compared with medium control; $* * p<0.001$ compared with corresponding TGF- $\beta 1$.
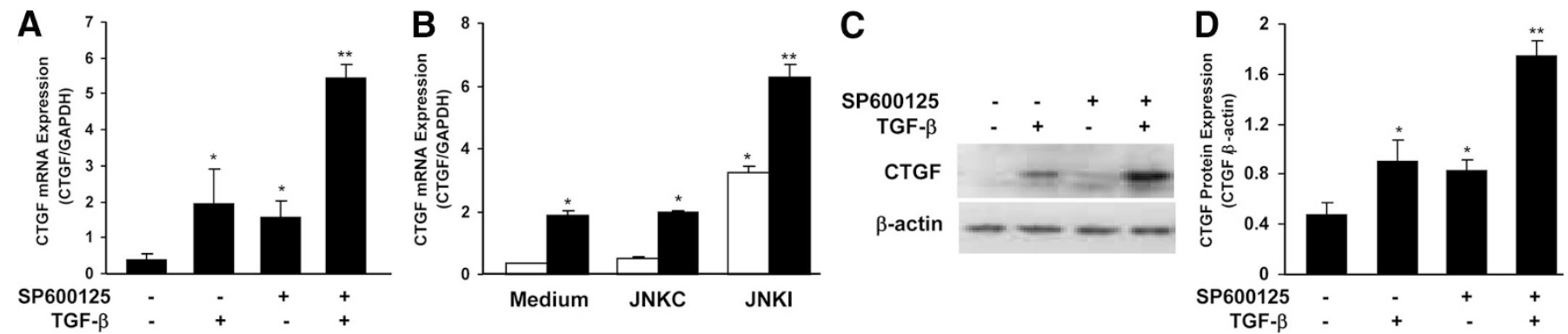

Figure 4. JNK inhibitors induce endogenous CTGF expression and enhance TGF- $\beta 1$-induced CTGF expression. E12.5 lung explants were treated with $10 \mu \mathrm{M}$ SP600125, $10 \mu \mathrm{M} \mathrm{JNKC,} 10 \mu \mathrm{M}$ JNKI, $100 \mathrm{ng} / \mathrm{mL}$ TGF- $\beta$, or their combination for $48 \mathrm{~h}$. $A, B$ : CTGF mRNA expression determined by quantitative real-time RT-PCR and normalization to GAPDH. Open bar, medium; Solid bar, TGF- $\beta 1$. C: CTGF protein expression determined by Western blot and $(D)$ normalization to $\beta$-actin. Each bar represents mean \pm SD from three independent experiments. ${ }^{*} p<0.01$ compared with medium control; ** $p<0.001$ compared with TGF- $\beta 1$. 


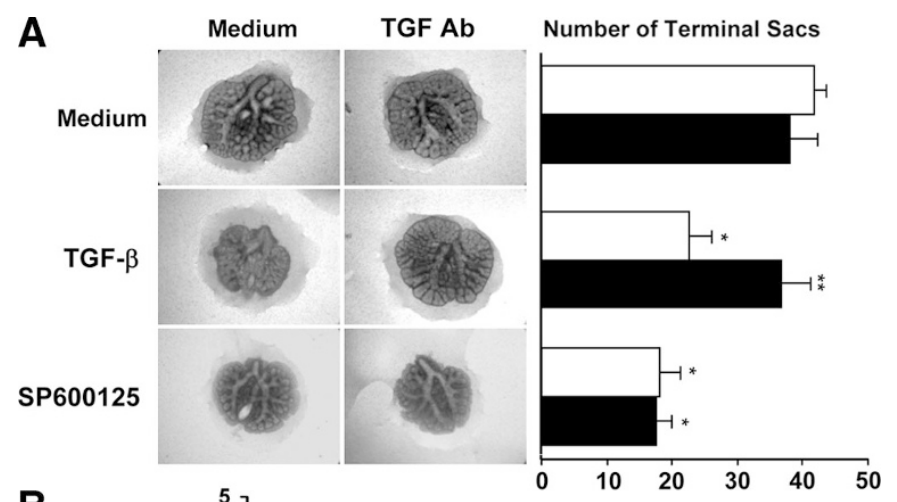

B

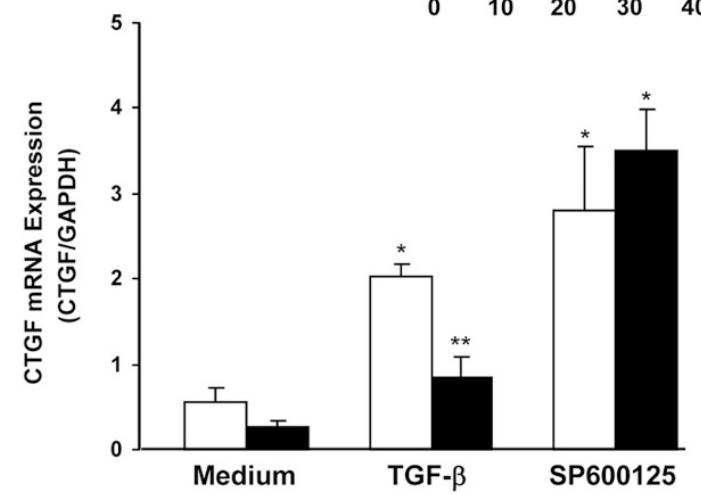

Figure 5. Anti-TGF- $\beta$ antibody does not block SP600125 inhibition of branching morphogenesis and induction of CTGF expression. E12.5 lung explants were preincubated with medium (open bar) or an anti-TGF antibody (solid bar) for $1 \mathrm{~h}$ and then treated with $100 \mathrm{ng} / \mathrm{mL}$ TGF- $\beta 1$ or $10 \mu \mathrm{M}$ SP600125 for 48 h. A: Branching morphogenesis. Each bar represents mean $\pm \mathrm{SD}$ from six lung explants. $* p<0.001$ compared with control; ** $p<$ 0.001 compared with TGF- $\beta 1$. B: CTGF mRNA expression determined by quantitative real-time RT-PCR and normalization to GAPDH. Each bar represents mean $\pm \mathrm{SD}$ from three independent experiments. $* p<0.001$ compared with control; **p $<0.05$ compared with TGF- $\beta 1$.

the JNK pathway induces endogenous CTGF gene expression and also enhances TGF- $\beta 1$-induced CTGF gene expression in embryonic lung explants.

Blocking the JNK pathway does not affect TGF-ß gene expression and TGF- $\beta$ binding to its receptors. To determine whether blocking the JNK pathway in mouse embryonic lung explants triggers TGF- $\beta$ autoregulation, we measured mRNA expression of TGF- $\beta 1,2,3, \mathrm{~T} \beta \mathrm{RI}$, and T $\beta$ RII. Treatment with either TGF- $\beta 1$ or SP600125 or their combination did not significantly change mRNA expression of these genes (data not shown). To determine whether enhanced branching inhibition and CTGF mRNA expression caused by JNK inhibition is mediated by increased TGF- $\beta$ binding to its receptors, lung explants were pretreated with a TGF- $\beta$ neutralizing antibody and then treated with TGF- $\beta 1$ or SP600125. As demonstrated in Figure 5, pretreatment with the antibody significantly blocked TGF- $\beta 1$ inhibition of branching. However, the antibody had no effect on branching inhibition caused by SP600125. Correlating with branching morphogenesis, TGF- $\beta$ antibody abolished TGF- $\beta 1$-induced CTGF mRNA expression, but had no effect on SP600125-induced CTGF mRNA expression (Fig. 5).

Blocking the JNK pathway induces apoptosis. To investigate the potential mechanisms of the decreased branching morphogenesis caused by JNK inhibition and TGF- $\beta 1$, apo-

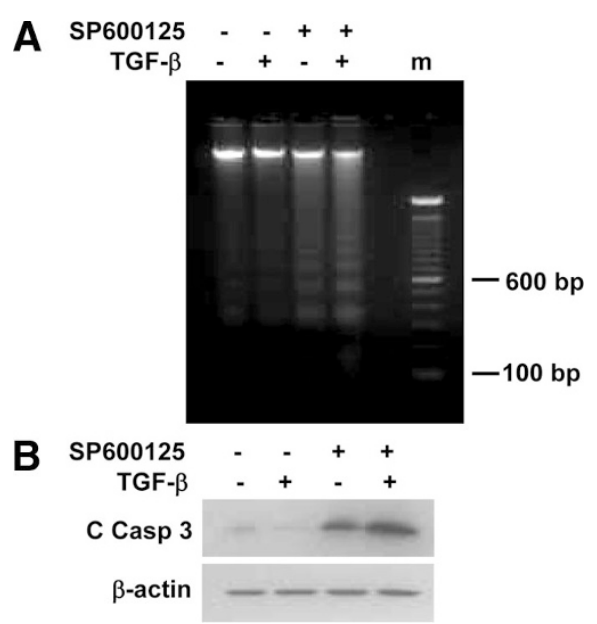

Figure 6. JNK inhibition induces apoptosis. E12.5 lung explants were treated with $10 \mu \mathrm{M}$ SP $600125,100 \mathrm{ng} / \mathrm{mL}$ TGF- $\beta$, or their combination for $48 \mathrm{~h}$. A: DNA fragmentation analyzed by agarose gel electrophoresis. m, 100 bp DNA molecular weight markers. $B$ : Western blot analysis of cleaved caspase 3 (C Casp 3) expression.

ptosis was examined by DNA fragmentation assay and expression of cleaved caspase 3, a crucial effector of apoptosis cascades (33). Treatment with SP600125 resulted in DNA internucleosomal cleavage as demonstrated by ladder appearance of low molecular weight DNAs on agarose gel electrophoresis (Fig. 6). Treatment with SP600125 also induced expression of cleaved caspase 3 (Fig. 6). In contrast, treatment with TGF- $\beta$ did not induce apoptosis.

\section{DISCUSSION}

The Smad family of proteins is thought to be the primary intracellular mediators of TGF- $\beta$ signaling. However, increasing evidence indicates that TGF- $\beta$ can also activate MAPK cascades and that cross talk between the Smad pathway and MAPKs determines the overall cellular responses to TGF- $\beta$. Among the MAPKs, the best characterized is the JNK signaling pathway, but its role in embryonic lung development is largely unknown. Thus, we have investigated the effects of JNK inhibition on TGF- $\beta$ responsiveness during embryonic lung development. We focused our investigations on branching morphogenesis and CTGF gene expression because our previous study showed that these two responses are Smad2dependent (22). The data from this study demonstrate for the first time that TGF- $\beta$ activates the JNK pathway, inhibition of this pathway enhances TGF- $\beta 1$-Smad 2 responses in mouse embryonic lung explants.

In this study, we investigated whether TGF- $\beta 1$ activates the JNK pathway and showed that TGF- $\beta 1$ induces c-Jun phosphorylation in mouse embryonic lung explants. Moreover, SP600125 and JNKI, two well-characterized JNK inhibitors $(30,31)$, were found to effectively abolish TGF- $\beta 1$-induced c-Jun phosphorylation, confirming that TGF- $\beta 1$ activates the JNK pathway leading to c-Jun phosphorylation.

Multiple mechanisms have been reported by which the JNK pathway interacts with the Smad pathway to provide a negative feed back loop to control TGF- $\beta$ responses. In human hepatoma cell line HepG2, activation of the JNK pathway 
negatively regulates TGF- $\beta$ induced Smad signaling via c-Jun interacting with $\mathrm{Smad} 2 / 3$ corepressors such as TGIF and Ski $(34,35)$. In human dermal fibroblasts, 5-fluorouracil induces c-Jun phosphorylation and activation of AP-1 that inhibits Smad3/4 specific transcription and formation of Smad/DNA complex induced by TGF- $\beta$ (36). Furthermore, overexpression of JNK inhibits Smad2 phosphorylation, but lack of JNK induces Smad2 phosphorylation in fibroblasts (37). In previous studies, we demonstrated that TGF- $\beta 1$ induces Smad2 phosphorylation in mouse embryonic lung explants (22). In this study, we investigated whether JNK inhibition affects Smad2 phosphorylation. We showed that SP600125 induces endogenous Smad2 phosphorylation and enhances TGF- $\beta 1$-induced Smad2 phosphorylation. However, we did not observe any effect of JNKI on Smad2 phosphorylation. One possible explanation for the differential effect of SP600125 and JNKI on Smad2 phosphorylation may be that SP600125 and JNKI act differently to inhibit the JNK pathway. SP600125 inhibits JNK phosphorylation of c-Jun (IC 50 of 0.04 ), and to a lesser degree inhibits MKK4 phosphorylation of JNK (IC50 of 0.4) (30). In contrast, JNKI blocks the interaction between JNK and c-Jun, but has no effect on MKK4 phosphorylation of JNK (31). These may explain why SP600125 and JNKI both inhibited c-Jun phosphorylation but only SP600125 induced Smad2 phosphorylation in this study.

The biologic significance of the Smad2/3 pathway in regulating branching morphogenesis is well documented and multiple lines of evidence indicate that activation of the Smad2/3 pathway inhibits branching morphogenesis $(22,23)$. Accordingly, we also investigated whether JNK inhibition influences branching morphogenesis in embryonic lung explants. The results showed that blocking the JNK pathway inhibited normal branching morphogenesis and enhanced TGF- $\beta 1$ inhibition of branching. Extensive studies have demonstrated that the JNK pathway plays a critical role in modulating cell death. A recent study has shown that activation of JNK promotes cell survival during short bursts of oxidative stress, and that JNK inhibition accelerates caspase-3 and -9 cleavage, which triggers apoptosis in primary culture of rat neonatal cardiomyocytes (33). Data from this study demonstrated that JNK inhibition alone or in the presence of TGF- $\beta 1$ results in apoptosis in embryonic lung explants. In contrast, treatment with TGF- $\beta 1$ alone did not cause apoptosis. The differential effects of JNK inhibition and TGF- $\beta$ on apoptosis observed in this study suggest that the Smad-independent mechanisms are also involved in JNK action during embryonic lung development. Future studies are needed to explore the potential mechanisms by which the JNK pathway modulates cell proliferation and apoptosis in embryonic lung branching morphogenesis.

CTGF is a TGF- $\beta$ responsive gene that mediates many of the TGF- $\beta$ effects on mesenchymal cell types (26-29). The Smad2/3 pathway plays a key role in TGF- $\beta$ induction of CTGF expression (38,39). A functional Smad element is found in the CTGF promoter and it can be potently activated by Smad2/3 and suppressed by Smad7 (38). The JNK pathway is implicated to play both agonistic and antagonistic roles in TGF- $\beta 1$ induction of CTGF expression. It has been reported that induction of CTGF by TGF- $\beta$ is antagonized by hyperactive JNK and AP-1. This involves c-Jun binding to Smad2/3, blocking its interaction with the Smad element of the CTGF promoter (39). However, studies have also demonstrated that TGF- $\beta$ activation of Smad2 and induction of CTGF in human lung fibroblasts is attenuated by JNK inhibition (40). Our previous studies have demonstrated that induction of CTGF expression by TGF- $\beta 1$ in embryonic lung explants is Smad-dependent (22). In this study, we investigated whether inhibition of the JNK pathway induces CTGF gene expression in mouse embryonic lung explants and found this to be the case in both the basal and TGF- $\beta 1$-induced states. Thus, the increased Smad2 activity and decreased c-Jun activity caused by JNK inhibition plays an agonistic role in TGF- $\beta$ induction of CTGF expression in embryonic lung explants. This is different from what has been reported in mature lung fibroblasts (40).

Previous studies have indicated that JNK disruption results in TGF- $\beta$ autoregulation (37). To elucidate additional potential mechanisms by which JNK inhibition enhances Smad2 signaling in embryonic lung explants, we examined TGF- $\beta$ autoregulation in this study. Our results demonstrated that JNK inhibition does not alter expression of TGF- $\beta$ ligands and receptors. Furthermore, JNK inhibition did not affect TGF- $\beta$ s binding to their receptors. Therefore, the decreased branching and increased CTGF gene expression caused by JNK inhibition are unlikely the results of TGF- $\beta$ autoregulation.

In conclusion, our results demonstrate that blocking the endogenous JNK pathway inhibits branching morphogenesis and induces CTGF gene expression in embryonic lung explants. Furthermore, blocking the TGF- $\beta$ 1-induced JNK pathway enhances Smad2 phosphorylation, decreases branching morphogenesis, and increases CTGF gene expression. These data suggest that the JNK pathway antagonizes the Smad2/3 pathway to modulate TGF- $\beta$ responses in lung branching morphogenesis.

\section{REFERENCES}

1. Moses HL 1990 Growth Factors from Genes to Clinical Application. Raven Press, New York. pp 141-155

2. Moses HL, Yang EY, Pietenpol JA 1990 TGF-beta stimulation and inhibition of cell proliferation: new mechanistic insights. Cell 63:245-247

3. Zhou L, Dey CR, Wert SE, Whitsett JA 1996 Arrested lung morphogenesis in transgenic mice bearing a SP-C-TGF-beta 1 chimeric gene. Dev Biol 175:227-238

4. Zeng X, Gray M, Stahlman MT, Whitsett JA 2001 TGF-beta1 perturbs vascular development and inhibits epithelial differentiation in fetal lung in vivo. Dev Dyn 221:289-301

5. Serra R, Pelton RW, Moses HL 1994 TGF beta 1 inhibits branching morphogenesis and n-myc expression in lung bud organ cultures. Development 120:2153-2161

6. Bragg AD, Moses HL, Serra R 2001 Signaling to the epithelium is not sufficient to mediate all of the effects of transforming growth factor beta and bone morphogenetic protein 4 on murine embryonic lung development. Mech Dev 109:13-26

7. Zhao J, Bu D, Lee M, Slavkin HC, Hall FL, Warburton D 1996 Abrogation of transforming growth factor-beta type II receptor stimulates embryonic mouse lung branching morphogenesis in culture. Dev Biol 180:242-257

8. Massague J, Cheifetz S, Boyd FT, Andres LJ 1990 TGF-beta receptors and TGF-beta binding proteoglycans: recent progress in identifying their functional properties. Ann NY Acad Sci 593:59-72

9. Franzen P, ten Dijke P, Ichijo H, Yamashita H, Schulz P, Heldin CH, Miyazono K 1993 Cloning of a TGF beta type I receptor that forms a heteromeric complex with the TGF beta type II receptor. Cell 75:681-692

10. Massague J 1998 TGF-beta signal transduction. Annu Rev Biochem 67:753-791

11. Massague J, Chen YG 2000 Controlling TGF-beta signaling. Genes Dev 14:627644

12. Afrakhte M, Moren A, Jossan S, Itoh S, Sampath K, Westermark B, Heldin CH, Heldin NE, ten Dijke P 1998 Induction of inhibitory Smad6 and Smad7 mRNA by TGF-beta family members. Biochem Biophys Res Commun 249:505-511 
13. Derynck R, Zhang YE 2003 Smad-dependent and Smad-independent pathways in TGF- $\beta$ signaling. Nature 425:577-584

14. Moustakas A, Heldin CH 2005 Non-Smad TGF- $\beta$ signals. J Cell Sci 118:3573-3584

15. Watanabe H, de Caestecker MP, Yamada Y 2001 Transcriptional cross-talk between Smad, erk1/2, and p38 mitogen-activated protein kinase pathways regulates transforming growth factor-beta-induced aggrecan gene expression in chondrogenic atdc5 cells. J Biol Chem 276:14466-14473

16. Kale VP 2004 Differential activation of MAPK signaling pathways by TGF-betal forms the molecular mechanism behind its dose-dependent bidirectional effects on hematopoiesis. Stem Cells Dev 13:27-38

17. Davis RJ 2000 Signal transduction by the JNK group of MAP kinases. Cell 103:239-252

18. Angel P, Hattori K, Smeal T, Karin M 1988 The jun proto-oncogene is positively autoregulated by its product, Jun/AP-1. Cell 55:875-885

19. Derijard B, Hibi M, Wu IH, Barrett T, Su B, Deng T, Karin M, Davis RJ 1994 JNK1: a protein kinase stimulated by UV light and Ha-Ras that binds and phosphorylates the c-Jun activation domain. Cell 76:1025-1037

20. Zhang Y, Feng XH, Derynck R 1998 Smad3 and Smad4 cooperate with c-jun/c-fos to mediateTGF-beta-induced transcription. Nature 394:909-913

21. Engel ME, McDonnell MA, Law BK, Moses HL 1999 Interdependent Smad and JNK signaling in transforming growth factor-beta-mediated transcription. J Biol Chem 274:37413-37420

22. Wu S, Peng J, Duncan MR, Kasisomayajula K, Grotendorst G, Bancalari E 2007 Alk-5 mediates endogenous and tgf-beta1-induced expression of connective tissue growth factor in embryonic lung. Am J Respir Cell Mol Biol 36:552-561

23. Zhao J, Lee M, Smith S, Warburton D 1998 Abrogation of Smad3 and Smad2 or of Smad4 gene expression positively regulates murine embryonic lung branching morphogenesis in culture. Dev Biol 194:182-195

24. Bork P 1993 The modular architecture of a new family of growth regulators related to connective tissue growth factor. FEBS Lett 327:125-130

25. Leask A, Abraham DJ 2003 The role of connective tissue growth factor, a multifunctional matricellular protein, in fibroblast biology. Biochem Cell Biol 81:355363

26. Grotendorst GR 1997 Connective tissue growth factor: a mediator of TGF-beta action on fibroblasts. Cytokine Growth Factor Rev 8:171-179

27. Kothapalli D, Hayashi N, Grotendorst GR 1998 Inhibition of TGF-beta-stimulated CTGF gene expression and anchorage-independent growth by cAMP identifies a CTGF-dependent restriction point in the cell cycle. FASEB J 12:1151-1161

28. Duncan MR, Frazier KS, Abramson S, Williams S, Klapper H, Huang X, Grotendorst GR 1999 Connective tissue growth factor mediates transforming growth factor beta-induced collagen synthesis: down-regulation by cAMP. FASEB J 13:17741786

29. Grotendorst GR, Rahmanie H, Duncan MR 2004 Combinatorial signaling pathways determine fibroblast proliferation and myofibroblast differentiation. FASEB 18:469-479

30. Bennett BL, Sasaki DT, Murray BW, O’Leary EC, Sakata ST, Xu W, Leisten JC, Motiwala A, Pierce S, Satoh Y 2001 SP600125, an anthrapyrazolone inhibitor of jun n-terminal kinase. Proc Natl Acad Sci USA 98:13681-13686

31. Bonny C, Oberson A, Negri S, Sauser C, Schorderet DF 2001 Cell-permeable peptide inhibitors of JNK: novel blockers of beta-cell death. Diabetes 50:77-82

32. Hamada M, Sumi T, Iwai S, Nakazawa M, Yura Y 2006 Induction of endonuclease G-medictaed apoptosis in human oral sequamous cell carcinoma cells by protein kinase C inhibitor satingol. Apoptosis 11:47-56

33. Tran TH, Andreka P, Rodrigues CO, Webster KA, Bishopric NH 2007 Jun kinase delay caspase-9 activation by interaction with apoptosome. J Biol Chem 282:20340 20350

34. Pessah M, Prunier C, Marais J, Ferrand N, Mazars A, Lallemand F, Gauthier JM, Atfi A 2001 C-jun interacts with the corepressor TG-interacting factor (TGIF) to suppress Smad2 transcriptional activity. Proc Natl Acad Sci USA 98:6198-6203

35. Pessah M, Marais J, Prunier C, Ferrand N, Lallemand F, Mauviel A, Atfi A 2002 $\mathrm{C}$-jun associates with the oncoprotein ski and suppresses Smad2 transcriptional activity. J Biol Chem 277:29094-29100

36. Wendling J, Marchand A, Mauviel A, Verrecchia F 2003 5-fluorouracil blocks transforming growth factor-beta-induced alpha 2 type I collagen gene (COL1A2) expression in human fibroblasts via c-Jun NH2-terminal kinase/activator protein-1 activation. Mol Pharmacol 64:707-713

37. Ventura JJ, Kennedy NJ, Flavell RA, Davis RJ 2004 JNK regulates autocrine expression of TGF-beta1. Mol Cell 15:269-278

38. Holmes A, Abraham DJ, Sa S, Shiwen X, Black CM, Leask A 2001 CTGF an SMADs, maintenance of scleroderma phenotype is independent of SMAD signaling. J Biol Chem 276:10594-10601

39. Leask A, Holmes A, Black CM, Abraham DJ 2003 Connective tissue growth factor gene expression: requirments for its induction by transforming growth factor- $\beta 2$ in fibroblasts. J Biol Chem 278:13008-13015

40. Utsugi M, Dobashi K, Ishizuka T, Masubuchic K, Shimizu Y, Nakazawa T, Mori M 2003 C-Jun-NH2-terminal kinase mediates expression of connective tissue growth factor induced by transforming growth factor-betal in human lung fibroblasts. Am J Respir Cell Mol Biol 28:754-76 